CERE Working Paper, 2016:16

\title{
The economics of the European Water Framework Directive - A retrospective remark focusing on Sweden
}

\author{
Kristina Ek ${ }^{\mathrm{a}}$ and Lars Persson ${ }^{\mathrm{b}}$
}

${ }^{a}$ Economics Unit, Luleå University of Technology, Sweden

${ }^{b}$ Department of Economics, and Centre for Environmental and Resource Economics

The Centre for Environmental and Resource Economics (CERE) is an inter-disciplinary and inter-university research centre at the Umeå Campus: Umeå University and the Swedish University of Agricultural Sciences. The main objectives with the Centre are to tie together research groups at the different departments and universities; provide seminars and workshops within the field of environmental \& resource economics and management; and constitute a platform for a creative and strong research environment within the field.

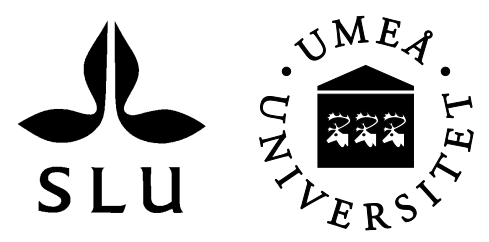




\title{
The economics of the European Water Framework Directive
}

\section{- A retrospective remark focusing on Sweden}

\author{
Kristina Ek ${ }^{\mathrm{a}}$ and Lars Persson ${ }^{\mathrm{b}}$ \\ a Economics Unit, Luleå University of Technology, Sweden \\ b Department of Economics, and Centre for Environmental and Resource Economics, \\ Umeå University, Sweden
}

\begin{abstract}
The Water Framework Directive (WFD) explicitly acknowledges the role of economics in the process of reaching the environmental quality objectives. The purpose of this paper is to discuss the implementation of the WFD in Sweden based on standard economic theory regarding instruments for cost efficient- and effective solutions to environmental problems. A lesson is that although incentive based instruments are beneficial from a cost-efficiency perspective, the complexities associated with environmental water management may somewhat challenge their implementation. Flexibility is a key issue for cost-effectiveness and, since Swedish water management mainly consists of command-and control instruments, the cost effectiveness is likely to be limited. Furthermore, the paper also points at how policy instruments relate to the economic burden aspect and the PPP - both highlighted in the Directive.
\end{abstract}

Keywords: The economics of the Water Framework Directive; cost efficiency and effectiveness; environmental water management; Polluter Pays Principle 


\section{Introduction}

According to the European Water Framework Directive (WFD), all water bodies (surface waters, groundwater, estuaries, and coastal waters) should have been in ecologically and chemically good status by 2015 (European Commission, 2000). Although the larger part of the WFD focuses on ecological issues, it explicitly acknowledges the role of economics when reaching environmental quality objectives; it calls for the application of economic principles, methods and tools, and for the consideration of economic instruments ${ }^{1}$ to reach good water status in Europe in the most cost-effective way (European Commission, 2000). Member states are for instance required to develop river basin management plans, to set environmental (water quality) goals or standards, and to identify measures to achieve good status. The WFD further states that all costs should be covered, and that measures should be judged by cost effectiveness criteria and the polluter pays principle (PPP). With the above focus on cost effectiveness and PPP as a point of reference, the purpose of the present paper is to (i) give a short introduction to basic economic theory regarding efficient and cost-effective policies for environmental problems, and (ii) discuss aspects of the Swedish implementation of the WFD. The paper fills a gap in the literature since it is hard to find general and retrospective comments on the implementation of the Directive from an economic perspective, not the least from a Swedish standpoint.

For a number of reasons (which will be further discussed following sections), the operationalization of the WFD is complex. The following sketch serves to illustrate a

\footnotetext{
${ }^{1}$ In this paper we distinguish between measures and instruments. Measures are interpreted as a product of the implementation of instruments. Specifically, instruments are designed to provide incentives for the relevant actors to choose measures such as filtering, installation of new technology, etc., in a way such that targets are reached.
} 
simplified, but still relevant, starting point for the analysis of water quality issues and policies.

Figure 1

Starting from the polluters, illustrated by factories and individuals, they give rise to multiple pollutants and other environmental water problems (P1, P2, P3). Emissions can be seen as stemming from different point- and nonpoint sources ${ }^{2}$ that do not necessarily have a one-to-one relationship to ambient levels of pollutants in water bodies. In addition to pollution, physical disturbances from e.g. hydroelectric schemes may constitute obstacles for reaching good water quality. Preventing the water from streaming creates fragmentation of fish and other species, which pose a threat to biodiversity. A number of different environmental criteria (chemical and ecological) are aggregated to define whether the water is classified as good or not. In case of not reaching good status, the situation calls for policy instruments and other measures to be implemented. There are a variety of available instruments and measures that can be implemented such as administrative and legal standards and controls, economic and fiscal instruments, management measures and capital works. Finally, figure 1 serves to illustrate that a single instrument or measure possibly have multiple effects on different sources of water problems. Instruments or measures will also differ with respect to the costs they imply for society and with regard to how costs are shared across different actors.

\footnotetext{
${ }^{2} \mathrm{~A}$ point source of pollution is actually a legal definition but can in general be interpreted as pollution from a confined and discrete conveyance via e.g. a pipe, channel, container etc. A nonpoint source of pollution, on the other hand, comes from many diffuse sources. An illustrative example could be polluted rainfall or snowmelt moving over land picking up varieties of pollutants.
} 
To consider the role of economics in the WFD it is important to separate between the concepts of social efficiency and cost-effectiveness. Social efficiency relates to policies determined to maximize the overall social utility (benefits in relation to costs), whereas cost effectiveness refers to reaching goals/targets at the lowest possible cost for the society (including private and external costs). It must be noted that cost-effective measures are not the same as cheap measures; reaching an ambitious target may imply substantial costs while still being cost-effective.

The WFD defines a number of specific sub goals/criteria, which together define water status. In spite the emphasis on economic concepts, the WFD should be considered as an ecological directive driven by, and based on, ecological principles of sustainable water management (see e.g. Brouwer, 2008). The environmental goals are not based on criteria related to social and economic efficiency. Moreover, the more or less absolute goals in the directive implicitly attach an infinite value of reaching the goal, whereas any point beyond the goal has a zero value. To consider any value for reaching above the goals/criteria, the analysis would need to have its standpoint in social efficiency instead of solely focusing on cost effectiveness.

Section 2 summarises a selection of studies on the assessment of the WFD and costeffectiveness while section 3 explains the reasoning underlying the concepts of economic efficiency and cost effectiveness. Section 4 discusses the implementation of the WFD in Sweden from the perspectives of cost effectiveness and PPP, as well as the scope for increasing the cost effectiveness and the costs carried by the polluters. The $5^{\text {th }}$ and last section concludes the paper. 


\section{Literature related to cost-effectiveness and the implementation of the WFD}

The directive explicitly stresses the importance of economic considerations and it is therefore relevant to consider how such concepts are expressed and evaluated in the literature. Most studies seem to focus on cost effectiveness while studies evaluating both the societal benefits and costs of improved water quality are scarcer. Andrews et al. (2002) is one exception; when estimating the expected benefits and costs associated with the implementation of the WFD in Scotland they find that its implementation would generate positive net benefits at the national level. Brouwer (2008) analyses the costs and benefits of implementing the WFD in the Netherlands and the results suggest that net benefits are negative. Hanley and Black (2006) compare the societal costs and benefits across three local case studies on so-called heavily modified water bodies and one national study in Scotland. Their results indicate (again) that the implementation of the WFD in Scotland generates positive net benefits at a national level, while the results at the local level are ambiguous.

Turning to the cost-effectiveness related literature, there are examples of handbooktype studies aiming at supporting decision makers by developing methods for how the complex task of choosing cost-effective measures could be put into practice (see e.g. Goodbody Economic Consultants, 2008; Interwies et al., 2003; Postle et al., 2005). The methodological frameworks set up in these studies are generally complex, mapping a number of different expected effects associated with all the measures considered to be available to improve water quality in a specific water body. None of these quite extensive methodological reports/handbooks refers to economic theory. Neither do they discuss the cost-effectiveness of incentive based instruments, nor do they discuss the role of flexibility for cost-effectiveness (Goodbody Economic Consultants, 2008; 
Interwies et al., 2003; Postle et al., 2005). Instead, the implicit assumption seems to be that a well-informed decision maker should make the complex choice to find the most cost-effective measure.

Dworak and Pielen (2006) explicitly discuss incentive based instruments and highlight the challenges related to scale in water management. They discuss how technical measures at local scale can be integrated with incentive based instruments implemented at a national or regional level. (Dworak and Pielen, 2006).

There are a number of case studies on the cost-effectiveness of measures available in environmental water management, although they typically focus on specific attributes (e.g., substances) of the overall goals. This could, for example, be about analysing the expected costs of measures that can be used to reduce nitrate or nitrogen (Brady 2003; Defra, 2004; van Engelen et al., 2008; Lacroix et al., 2005; Schmid and Sinabell, 2013). Van Engelen et al. (2008) analyse processes, qualitative versus quantitative, that can be used when selecting the most cost-effective measure, or combination of measures.

A significant share of the literature, as most of the studies mentioned here, focus on cost effectiveness from the perspective of a well-informed decision maker searching for the cost effective measure rather than focussing on implementing an incentive based instrument that will make individuals and firms change their behaviour in accordance with the goal. We will now discuss the cost efficiency and cost effectiveness of different types of environmental instruments from the perspective of basic economic theory. 


\section{Economic efficiency and cost-effectiveness ${ }^{3}$}

In many cases the private behaviour of agents (individuals, firms, etc.) does not only affect their own well-being but also the well-being of other agents - the behaviour is said to give rise to externalities. For example, think about a farmer that emits pollutants into a river and the polluted river has a negative effect on the fishermen in a downstream lake. The underlying problem is essentially that emitting pollutants is too cheap from the society's point of view and there are basically two initial tasks that the decision makers have to consider; what level of pollution is best for society and how to control the polluter in the best way. The following two sections (3.1 and 3.2) illustrate these decisions in relation to the concepts of efficiency and cost-effectiveness.

\subsection{Social efficiency and environmental goals}

It is perhaps tempting to argue that harmful behaviour should be totally avoided. However such argument overlooks that pollution often comes with benefits; in many cases the production of goods and services is not possible without generating at least some negative externalities such as pollution. Hence, trade-offs between positive production values and pollution are generally required. ${ }^{4}$ From the societies point of view (i.e. both the farmer and the fisherman in our example above) there is a level of emissions and fishing that maximizes total benefits (i.e., profits received by both the fisherman and the farmer). If a decision maker could: (a) determine the level of pollution

\footnotetext{
${ }^{3}$ Section 2 is written with the inspiration of the standard textbooks in the field of environmental and resource economics. Examples of such textbooks are Hanley et al. (2007), Kolstad (2011) and Perman et al. (1999).

${ }^{4}$ There are special cases where it can be optimal to have no pollution at all. One example is when the cost of damage is extremely large, meaning that the first unit produced has a higher environmental cost than its value in terms of consumption. Another example would be if the value of the produced good is extremely low, meaning that the analysis becomes sensitive for small environmental costs.
} 
that maximizes benefits in the society and, (b) make the farmer choose that level of emissions, the solution is said to be socially optimal or socially efficient.

The determination of the socially efficient level of pollution involves the calculation of all relevant private and external costs and benefits, which is a non-trivial task in any real world scenario. Regarding water management the complexity is further enhanced since the environmental goal of good water status is, in itself, defined by a number of targets or standards (based on ecological and chemical factors) that can be interrelated. The ecological standard may consist of a number of characteristics such as minimum levels of richness in species, standard of riverbeds, presence of litter, etc., while chemical status generally is defined in terms of maximum levels of different hazardous substances. The fact that many of the standards and goals under the joint umbrella of good water status are interrelated (potentially also the case for the corresponding measures) complicates the choice of cost-effective measures. Geijer (2013) analyses the problem of eutrophication, which is mainly caused by leakage of nitrogen and phosphorous. The choice of measures targeted at eutrophication is complicated by the fact that measures targeted towards nitrogen also affect emissions of phosphorous. The desired level of phosphorous is thus a function of the acquired level of nitrogen and vice versa. This interdependence implies that we should analyse how to reach the goals for nitrogen and phosphorous simultaneously. The cost of achieving a multiple goal for eutrophication may well be different from the sum of the costs associated with reaching the two goals separately.

As described above, the definition of a socially efficient solution demands a valuation of both costs and benefits. For many environmental resources, there is no explicit market 
determining prices but as long as people derive utility from e.g. the services provided by good water status there is a value attached to it. These values should be put in relation to the costs in order to define a socially optimal goal or target. Non-market values, or services, call for methods to estimate the value of the good or service (examples are stated preferences, hedonic pricing, etc., where "consumers" reveal or state preferences that can be normalized to a common monetary unit).

The WFD already defines more or less precise goals and targets and therefore it is not, at this stage, relevant to value costs and benefits to find the optimal level of water status. Instead, the focus is on how to reach these goals at lowest social cost; the relevant goal is thus cost effectiveness for each sub-goal rather than analysing socially efficient goals. Although the goal of good water status in itself consists of different sub goals there is typically not an overall assessment made when the water status is reviewed. This means that each standard, or sub goal, must be fulfilled if the water status is to be regarded as good. Although the fulfilment of each sub goal (probably) is desirable, it may take time to reach the good status and decision makers at different levels need to prioritize across different instruments or measures targeted to different aspects of the water quality. The WFD does not provide any guidance to decision makers in member states about how such priorities should be made. A somewhat complicating matter with fixed goals is however that the value of obtaining the goal is, in principle, infinite and all measures therefore become relevant alternatives, while there is a zero value of reaching a better status than specified by the directive. ${ }^{5}$

\footnotetext{
${ }^{5}$ Another complicating matter is that although the WFD as such specifies goals and targets, there is a potentially discrepancy in the practical implementation with regard to judiciary interpretations, political discretion and biological measurement uncertainties. These complications are however not considered in this paper.
} 


\subsection{Cost-effectiveness and flexibility in measures}

Leaving aside some of the complexities mentioned above and considering goals and targets as fixed, the next step is to choose the appropriate, i.e. cost effective instruments. The choice of appropriate instruments is about designing instruments that create the correct incentives for agents affecting water quality, e.g. the polluters. Given correct incentives, polluters strive for the relevant demands and targets in a cost effective way.

\subsubsection{Regulations}

Regulations are perhaps the first suggestion when it comes to curbing emission and it is also likely to be the most common form of environmental regulation in real world policies. The method is denoted command-and-control since the regulator (e.g. a government) defines actions to control e.g. water pollution and then commands the polluter to take the necessary actions. In practice, regulations (as other policies) become complicated since the regulatory authority typically specifies for each new source of pollution what level of pollution to accept and how to control it. In other words, the regulatory authority needs to collect information for each and every pollutant and polluter to be able to define actions to obey.

Within the branch of regulations there are technological- and performance (prescriptive) regulations. Technological regulations define what technology (e.g. equipment) to use, while performance (prescriptive) regulations define e.g. the maximum amount pollutants to be emitted. Considering the flexibility at polluter level, performance regulations are in general preferred since they leave the choice of method to reduce emissions to the polluter. The polluter probably knows more than the regulator about the actual production technology and how to adjust to pre-specified 
demands. In all cases, it would otherwise impose a cost to the regulatory authority to investigate technologies, their associated costs and so on. If a firm is free to choose technology it will choose the one associated with the lowest costs, while the regulator with imperfect information may well stipulate a technology with higher costs. A technological regulation can therefore never outperform a quantitative regulation from a cost effectiveness perspective - the quantity constraint opens for the polluter to choose the lowest-cost technology. The only case when a technological constraint could be equally efficient is when the regulator has full information and knowledge about all possible technologies. Such a scenario is of course rather utopic and the relatively more flexible quantitative constraint is typically preferred.

Although performance (prescriptive) regulations are preferred over technological regulations from a cost effectiveness perspective, the cost effectiveness is likely to be limited also when regulations define the maximum amount of emitted pollutants. Again, the regulator is likely to have limited information about the abatement costs of different polluters, and to find a cost effective solution the regulator must have full information about the abatement cost of each polluter (unless they all have identical abatement costs). In an optimal outcome, pollution sources with low costs of abatement are given large quotas, while high-cost sources of pollution are given small quotas so that the marginal costs are equal across polluters. In practice however, a regulation may often imply that all polluters face an identical pollution limit, which will imply higher costs for society than necessary. Regulations are thus rarely optimal from a cost-effectiveness perspective. An important advantage with regulations is however that the pollution target can be reached for certain, which is not always the case for other types of policies such as emission taxes. 
Although the reduction of emissions posed by the regulation implies costs for most producers, there is no guarantee that costs and the amount of emissions are related to each other. A regulation often allows pollutants to be emitted to e.g. water resources for free as long as polluters are using the prescribed technology and/or do not exceed their maximum quota. Regulations can therefore be questioned not only on the basis of costeffectiveness, but also because they do not comply with the principle that the producer should pay for the abatement cost, i.e. the PPP, nor with the idea that all costs should be covered as stipulated by the WFD.

\subsubsection{Economic incentives}

In general, firms, farmers, etc., operate in a way such that costs and benefits are considered in many decisions. Without any restrictions, a typical producer acts according to the standard profit maximizing (cost minimization) condition where the revenue from the last unit equals the cost of producing that last unit. The problem from the society's point of view is the damage the production causes to e.g. water resources via emissions. The producer's cost function differs from the society's cost function, which includes both the private cost from the production and the societies cost for the damage caused by emissions. To make the producer act according to the social profit function, including the external cost of the emissions, the regulator can introduce a fee or a tax, corresponding to the marginal external cost that the production gives rise to. Correctly specified, the tax makes the producer's cost equal to the social cost. The producer reconsiders its production decision so that the price equal the marginal social cost instead of the marginal private cost. 
Ideally, economic incentives make polluters act as is desirable from the society's point of view. A fundamental difference between regulations and incentive based instruments is that the regulation defines how the target should be reached, while incentives allow for more flexibility, the polluter is free to adapt in what is considered to be the best and least costly way. This flexibility is a key argument for economic incentives being costeffective. Given the information asymmetry prevailing, creating incentives for polluters to choose what they consider to be the best and least costly strategy to reduce pollution will ensure that an environmental target will be reached at the lowest possible cost.

Emission fees or taxes are perhaps the most straightforward form of economic incentives; the polluter is charged with a fee/tax for each unit of emitted pollution. The fee/tax adds a cost to production and creates an incentive to reduce emissions. A difference compared to a regulation is that the regulation imposes a cost to the firm corresponding to the abatement, while the fee/tax imposes a cost for the amount not abated. This implies that with a fee/tax system there is an opportunity to redistribute from the producer to other actors in the society amounting to the revenues from the fee/tax. A fee/tax system is thus consistent with the PPP and, if the fee/tax corresponds to the marginal damage cost, with the idea that all costs should be covered. It is important to note that irrespectively of the source; emissions will be reduced as long as the abatement cost is lower than the fee/tax, i.e. until the marginal cost of reduction equals the cost of the fee/tax. Thinking about a scenario with a number of polluters with different technologies, and thereby different cost of abatement, a fee/tax will lead to a cost efficient allocation of emission reductions among the polluters. 
The information required for the regulator to achieve the target is the aggregate marginal cost function including both private and external costs for the society, and then the cost-effective allocation is obtained automatically via the fee/tax. This should be contrasted to the case of regulations where a cost-effective allocation requires the regulator also to have full information on individual polluter level. In other words, economic incentive strategies usually demand less information.

Another approach to change behaviour is to subsidize good behaviour and thus make bad behaviour (pollution) relatively more expensive. A subsidy also works to create economic incentives to control pollution. Examples are subsidies for new and clean technologies, certificate systems, abatement, etc. By comparison to an emission tax, a subsidy for each unit of reduced emission is the closest counterpart. In principle, from a cost-effectiveness perspective it should not matter whether imposing a tax on what's bad, or imposing a subsidy on what's good. ${ }^{6}$ When it comes to how the abatement costs are distributed there is however a difference. Subsidizing good behaviour generally implies that the taxpayers finance the subsidies and it is therefore not consistent with the PPP, nor does it comply with the idea that all costs should be paid for.

Apart from emission fees/taxes or subsidies, emission permits give the right to emit up to a given level; the holder of the permit has the right to emit polluting substances corresponding to the permit. The idea of emission permits is that the trading of permits induces a price on permits and polluters realize that polluting has a cost attached to it. The less pollution that you emit, the fewer permits you need. If it turns out that you

\footnotetext{
${ }^{6}$ While the subsidy creates incentives to reduce emissions at firm level, it may also attract other firms to the industry because of increased profits and thereby possibly increase total emissions from the industry as a whole.
} 
don't need all the permits, you may sell it on the market. The system of tradable permits is also called a "cap and trade" system because the regulative authority sets a "cap" on total emissions, and then allows for "trading" of permits. A tradable permit system gives rise to a situation where the marginal savings from emitting is equalized across polluters. Emission fees/taxes and tradable permits could in principle result in identical outcomes; they are both efficient from a social cost-effectiveness perspective. A difference is however that in a permit system the exact amount of pollution is known without knowing the marginal cost of control, while in an emission fee/tax system the marginal cost is known but not the exact quantity emitted. Whether the distribution of the costs using a tradable permit system is consistent with the PPP depends on whether the permits are granted freely or sold, or auctioned, to the polluters; the latter two alternatives do comply with the PPP while the first does not.

The third branch of economic incentives is economic liabilities, meaning that the agent causing the environmental problem must compensate for the damage. Liability rules can be defined in many ways but the idea is that it should create incentives for the agent causing the problem to adopt a preferable behaviour. Normally a liability rule is designed so that the potential agent, e.g. a polluter, pays an initial "insurance", which is repaid if no harm occurs, or as a non-compliance fee that is paid after/if the harm occurs. In other words, a liability rule creates an economic incentive since it gives rise to costs when the behaviour is harmful according to pre-defined parameters. A liability rule could be interpreted as a rather flexible system since the polluter has incentives to compensate or stop the harmful behaviour, while still free to decide on the methods. Since the agent causing the environmental problem pays the cost, either as insurance or 
as a non-compliance fee, a system with economic liabilities is consistent with the idea that all cost should be covered and with the principle that the polluter should pay.

\section{Cost-effectiveness and the implementation of the WFD in Sweden}

The message so far has been that regulations are not optimal from a cost-effectiveness perspective, nor do they comply with the principle that the polluter should bear the costs or that all costs should be covered (as stipulated by the WFD). On the contrary, it has been argued that incentive based instruments are more favourable from all three perspectives. The reasoning above is based on rather stylized setups and environmental water management in practice is an even more complicated task. Factors that complicate practical decisions relate to multiple goals, interrelated emissions and goals, existing regulations, political considerations, etc. Therefore, the general result drawn from economic theory about the cost-effectiveness of incentive based instruments is somewhat challenged. In practice, effective water management most likely involves economic incentives as well as additional measures. In this section we analyse existing instruments used in the implementation of the WFD in Sweden. The point of reference is cost-effectiveness, how the costs for improved water quality are distributed (i.e. whether the PPP is satisfied) and whether all costs are covered. We also discuss the potential for improved cost effectiveness.

\subsection{Existing instruments}

The WFD in Sweden is mainly implemented through regulations (SOU 2010:17). The overall aim of the Environmental Code, which is the most important environmental legislation in Sweden, is to promote sustainable development. According to the code all 
operators are required to take action so as to prevent, limit or resist inconvenience or harm to human health or the environment and the best available technology is prescribed, as long as it is not considered to be unreasonable. These requirements are reviewed in conjunction with the permit process actualised for all new water operations and for changes in production and e.g. emission levels for existing water operations. All water operations that affect water conditions, encompassing all physical measures such as constructions in water or land drainage, require permits. The permit system is an important instrument to reduce point source pollution of water resources in Sweden (SOU 2010:17). To be approved, the operator must show that the benefits are greater than the costs and damages associated with the operation at hand. When a permit is granted, it regulates the terms the operator must comply with, such as e.g. the highest allowed level of emissions or a prescription to use a specific technology.

Technological- and performance regulations governed by permits and their corresponding conditions are not likely to be cost-effective. As discussed in the previous section, polluters can be expected to know more about available technologies and associated costs than the regulating authority, meaning that requirements regarding specific technology-use may create additional costs. In addition, as long as performance regulations are not differentiated with regard to the abatement costs of different polluters, such regulations will still not be cost-effective (if not all polluters have identical abatement costs).

Moreover, a polluter with a permit to emit hazardous substances up to a maximum limit does not have to pay anything for the environmental costs the pollution may cause within the quota. Therefore, the regulations within the permit system neither succeed in 
having the polluter to pay, nor in having all cost covered (e.g. also external environmental costs).

To some extent, the Environmental Code leaves room also for compensatory measures. The basic principle is that the agent responsible for an activity must undertake the necessary measures to protect human health and the environment, which encompasses to restore damages caused by the activity. An attractive property with compensatory measures is that they offer flexibility; it may well be cost-effective to undertake measures for improving another characteristic of water quality, or to improve water quality in another site. This type of flexibility may be very attractive from the societies point of view, especially taking into account a potentially higher marginal value of improved quality at another site.

In addition to the permit system within the regulatory framework, primarily targeted towards point source water impacts, there are a number of taxes that indirectly affect water pollution caused by diffuse sources. These taxes are however not mainly motivated by water quality-related goals, instead some are motivated by combinations of fiscal and environmental reasons (e.g. property taxes for hydropower and wind power plants, taxes on electricity and fuels, etc.) while others are motivated primarily by other environmental motives than water quality (e.g. the carbon dioxide tax on fuels) (SOU 2010:17). Still, although motivated by other reasons than improving water quality, the incentive based instruments have the potential to contribute also to a cost-effective environmental water management. 
In 2010 a tax on fertilizers, initially introduced for environmental reasons, was abandoned for income distributional reasons; the tax on fertilizers was removed as a compensation for an increased tax on diesel (considered to have a negative impact on the agricultural sector). Although the tax on fertilizer was targeted towards the use of fertilizer (per kilo) rather than towards the leakage of hazardous substances, it had the potential to contribute to improved water quality in a cost-effective way. While the tax rate was not based on the size of the external costs (i.e. not complying with the idea that all costs should be covered), it did comply with the PPP.

Subsidies, mainly directed towards the agricultural sector, are also used in the implementation of the WFD in Sweden aiming to reduce leakage of nutrients and pesticides into water bodies. Farmers can, for example, apply for financial support for constructing so-called buffer zones; narrow permanently overgrown areas at the edges of fields located close to water bodies (Gyllström and Larsson, 2013). Since subsidies are available for all areas, independent of the societal value of their potential to reduce leakage of nutrients and pesticides, the cost-effectiveness is likely to be limited. There are examples of buffer zones in areas where it can be questioned if they have any effect (SOU 2010: 17). In addition, subsidizing polluters to undertake damage reducing measures can be questioned from a PPP perspective, and it is inconsistent with the idea that all costs should be paid for.

Given the implementation of the WFD in Sweden we conclude that there are a number of different instruments used to improve environmental water status. While the goal of good status in all water bodies by 2015 was not reached, existing instruments have to be sharpened and/or additional instruments have to be implemented in the future. In 
addition, the present system is not likely to be cost-effective. It is dominated by regulations while incentive based instruments are few (and primarily implemented by other motives than improved water quality). The permits granted under the Environmental Code is often detailed, not leaving much room for the producer to decide how to e.g. reduce pollution, nor differentiated with regard to cost differences. Moreover, emission quotas granted under the Environmental Code generally allow the producer to emit hazardous substances up to the quota without paying for the external cost that may arise, the permit system is thus not satisfying the principle that the polluter should pay for all the costs they infer, as stipulated by the WFD.

\subsection{The scope for increased cost effectiveness}

In general it is hard to target and measure pollution in such a way that it can be associated to a specific polluter. This means that in many cases it is difficult to target any policy instrument directly to the source of pollution, which is similar both for incentive based policies and regulations. A system similar to the one discussed by e.g. Segerson (1988) offers a potentially more realistic approach to address non-point pollution (works for point sources as well). The idea is to target a policy to ambient levels of pollutants in water bodies and to the aggregate of potential polluters, say within a certain area, that are put responsible for the water quality. In a situation with an already accepted level of emissions, granted for instance through a permit system as described above, a possible policy could be to introduce a tax for additional emissions, above the permit quota, and/or a subsidy for reduced emissions below the quota. Within the aggregate of polluters each member is assigned a share, which will be the base for the distribution of costs across the members. Based on this setup, the aggregate, via its members, works for an efficient distribution of emissions such that an agreement is 
obtained within the aggregate. In other words, it gives incentives for more collective actions that typically allow for flexibility and therefore are more cost effective. In case of actual emissions above the decided level, challenges might relate to how to distribute the cost for increased emissions, how to control and monitor behaviour etc. In a case of subsidizing reductions below the quota, a situation with reduced emissions may not give rise to equally difficult outcomes. In such a scenario, no member gets an increased cost from others' increased emissions meaning that it would be a question how to distribute the subsidy across members, which is likely to be a less challenging task than the corresponding distribution of additional costs. The proposed scheme would be flexible in the sense that it allows the polluters to freely choose what abatement techniques to use, which implies that abatement will be achieved at lowest possible cost. Moreover, since the scheme focuses on water quality rather than on emissions it provides incentives for polluters to try to offset peaks by, for instance, avoiding substantial fertilizer or pesticide applications prior to anticipated heavy rains.

The above structure would potentially work both for point- and non-point sources. In practice, the chance for a successful outcome depends on the size of the aggregate of polluters and the recipient area. A larger target area typically means a larger aggregate of polluters that, in turn, potentially complicates any agreement within the aggregate. Another possible solution to non-point sources would be the introduction of a tax on an indicator (rather than on the emissions), such as use of fertilizers. Although costefficient in theory, a complication is to exactly know the relation between the use of fertilizers and the final emission of problematic substances. Still, in cases where the transaction costs are too high for targeting policies directly to the actual emission, taxing indicators might be an acceptable solution. 
The scenarios outlined above are given an initial level of free emissions. Over time, this level can be changed (lowered) to increase pressure to reduce emissions and the environmental impact. This procedure also alters the cost of emissions to the polluters, while also giving the opportunity to adapt over time. It is worth mentioning that this type of system is close to a system with tradable permits. Tradable permits implies an increased certainty regarding the total amount of emissions, although it also creates uncertainty with respect to the "price" on emissions that may change over time in a cap and trade system.

Another possible change of the present system that may enhance cost effectiveness could be to introduce a tax on land and fields not having buffer zones, instead of subsidizing the establishment of buffer zones in general. In areas where buffer zones are considered important, each meter of fields without a buffer zone could for instance be taxed. Farmers facing high costs for establishing buffer zones could then choose to pay the tax instead of implementing the buffer zone.

On several occasions in this text, flexibility has been put forward as something important to reach cost effectiveness. Related to this is the possibility to allow for damaging activities given that it is compensated for in another area. An obvious complication is of course how to, in detail, determine the kind of compensation demanded. Another approach would be to instead introduce a monetary fee that, potentially together with payments from other polluters, may be used to start actions for improved environmental quality. 


\section{Concluding remarks}

Based on standard economic theory, this report has highlighted the concepts of economic efficiency, cost effectiveness and sharing of costs for improved water quality in relation to environmental water management. Given the design of the WFD it should have had a rather large impact on the implementation of instruments and measures over the last decade. In itself, this motivates some form of follow-up and evaluation initiated by governments, decision makers, etc. In addition, given the emphasis of the Directive on cost-effectiveness, the PPP and that all costs should be covered, the impression is that the Directive had economic incentive based instruments such as taxes in mind.

Although the directive stresses the role of economic tools, principles and measures, the goal of good water status is not based on a criterion of economic efficiency - it is based on ecological principles of environmental water management without any regard to their impact on social efficiency. The absolute targets based on ecological criteria implicitly set an infinite value of reaching the target, whereas reaching above the target (e.g., reaching high water status instead of good status) has a zero value. The impression is that most previous studies apply the cost effectiveness dimension to a single environmental criterion rather than on the overall water status (which in itself consists of a number of chemical and ecological criteria). The outcome of this type of analysis will thus potentially reveal which measure that generates the lowest expected cost for reaching the criteria. In practice however, it is not likely that all criteria will be met simultaneously. It is typically necessary for decision makers to prioritize between different effects and measures. The cost effectiveness analysis methodology does not assess differences in terms of the social value associated with different effects (i.e., the relative importance of criteria) and can therefore not be used to support such priorities. 
Flexibility is a key issue and the underlying reason for why economic incentives are preferred before regulations from a cost-effectiveness perspective. Given the prevailing information asymmetry, incentives for polluters to choose what they consider to be the best and least costly strategy to reduce pollution ensure that an environmental target will be reached at the lowest possible cost. It is important to strive for flexibility when measures and economic instruments are implemented within the WFD. Flexibility could, for example, refer to a polluter who undertakes compensating measures instead of being forced to handle a specific source of pollution. Although the complexities associated with environmental water management somewhat challenges the theoretically (text book) based claim that economic incentives are the most efficient and cost-effective way to solve environmental problems, there is scope for improved cost-effectiveness in general.

Turning to the Swedish water management, it should be possible to complement the existing system dominated by the permit processes regulated in the Environmental Code by subsidising emission levels below the quota and taxing levels exceeding the quota. There is also potential for improvement considering structural changes in the way we think of instruments. For example, instead of targeting "all" it may be attractive to instead target aggregate of polluters in a certain area, which are then made responsible for the water management (quality). This approach create incentives to reach more collective solutions and measures to quality issues which, in turn, lead to more cost effective outcomes. Implementing taxes on indicators (e.g. fertilizers) rather than emissions may also be beneficial from a cost-effectiveness perspective. All realistic scenarios are based on a given level of regulations and permissions but it is important to allow for a shift towards more incentive based policy structures. 
A seemingly often-neglected part of the WFD is the notion of burden of cost and polluter pays principle. In the present system, the operator incurs a cost for the measures undertaken to reduce their emissions rather than for the damage the emissions up to the quota may cause. Increasing the reliance on incentive based instruments would thus be in line with the principles that the polluters should pay for all the costs they generate and that all costs should be paid for.

The implementation of the WFD, which should be based on a river basin approach rather than on administrative boarders, will likely involve decisions on multiple levels and may require the use of incentive based instruments, regulations as well as combinations thereof. In this paper we claim that the cost-effectiveness of the Swedish implementation of the WFD is likely to be limited, pointing at the lack of assessments of the social efficiency of the Swedish environmental water management. Most research so far is however focussing on processes for how the implementation can and should be accomplished in order to contribute to societal resilience, legitimacy and cost effectiveness, while evaluations of the outcome of these desired states are rare. 


\section{References}

Andrews, K., Montgomerie, R., Hanley, N., and Black, A. (2002) Costs and benefits of the Water Framework Directive in Scotland. Downloaded August 2013, www.scotland.gov.uk/Publications/2002/07/15179.

Brady, M. (2003) The relative cost-efficiency of arable nitrogen management in Sweden. Ecological Economics, 47, pp. 53-70.

Brouwer, R. (2008) The potential role of stated preference methods in the Water Framework Directive to assess disproportionate costs. Journal of Environmental Planning and Management, 51, 5, pp. 597-614.

Defra (2004) Cost curve assessment of phosphorous mitigation options relevant to UK agriculture. Defra project code PE0203, UK.

Dworak, T., and Pielen, B. (2006) Selecting Cost-Effective Measures under the EU Water Framework Directive - The Issue of Scale. Discussion Paper of Leipzig University, Chair for Environmental Technology/Environmental Management.

European Commission (2000) Directive 2000/60/EC. Water Framework Directive. Official Journal of the European Communities.

Geijer, E. (2013) Eutrophication reduction from a more holistic perspective. CERE Working paper 2014:11.

Goodbody Economic Consultants (2008) Guidance on Implementing Cost Effectiveness of Measures in the Context of the Water Framework Directive. Downloaded May 2013, www.goodbody.ie.consultants.

Gyllström, M. and Larsson, M. (2013) Skyddszoner. Antaganden och metodik för beräkning av åtgärdspotential och kostnad. Vattenmyndigheterna och Länsstyrelserna. Downloaded May 2016, www.vattenmyndigheterna.se 
Hanley, N., and Black, A.R. (2006) Cost-Benefit Analysis and the Water Framework Directive in Scotland. Integrated Environmental Assessment and Management, 2, No. 2, pp. 156-165.

Hanley, N., Shogren, J. and White, B. (2007) Environmental economics in theory and practice. Second ed. Palgrave and Macmillan.

Interwies, E., Borchardt, D., Kraemer, A., Kranz, N., Görlach, B., Richter, S., Willecke, J.,and Dworak, T. (2003) Basic principles for selecting the most cost-effective combinations of measures for inclusion in the programme of measures as described in Article 11 of the Water Framework Directive - Handbook. Environmental research of the Federal Ministry of the Environment, Nature Conservation and Nuclear Safety, Research Report 20221210, UBA-FB 000563/E.

Kolstad, C. (2011) Intermediate environmental economics. International Second ed. Oxford university press.

Lacroix, A., Beaudoin, N., and Makowski, D. (2005) Agricultural water nonpoint pollution control under uncertainty and climate variability. Ecological Economics, 53, pp. 115127.

Perman, R., Yue, M., McGilvray, J. and Common, M (1999) Natural resource and environmental economics. Second ed. Pearson education limited.

Postle, M., Fenn, T., Foottit, A., Salado, R., Reid, S., Namzie, C., Leslie, J., Thornton, A., Hunt, D., Thorne, J., Interwies, E., Strosser, P., Görlach, B., Hull, S., and Freeman, S. (2005) Development of a Methodology to Determine the Cost-Effectiveness of Measures and Combinations of Measures for the Water Framework Directive (WFD). Combined CEA Methodology Report, A: Introduction, Prepared for The Collaborative Research Programme on River Basin Management Planning Economics. 
Schmid, E., and Sinabell, F. (2013) The European Water Framework Directive and programmes of cost effective measures - an application. Downloaded May 2013, www.webmeets.com/files/papers/ERE/WC3/959/WFD-Water-Quality.pdf

Segerson, K. (1988) Uncertainty and Incentives for Nonpoint Pollution Control. Journal of Environmental Economics and Management, 15, pp. 87-98.

SOU (Statens Offentliga Utredningar) (2010:17) Prissatt vatten? Betänkande av vattenprisutredningen. Stockholm.

Tietenberg, T. (2002) Environmental and Natural Resource Economics. $6^{\text {th }}$ edition, Addison Wesley.

van Engelen, D., Seidelin, C., van der Veeren, R., Barton, D.N., and Queb, K. (2008) Costeffectiveness analysis for the implementation of the EU Water Framework Directive. Water Policy, 10, pp. 207-220.

van der Veeren, R. (2010) Different cost-benefit analyses in The Netherlands for the European Water Framework Directive. Water Policy, 12, pp.747-760.

WATECO (2003) Common implementation strategy for the Water Framework Directive. Guidance Document No. 1. Economics and the environment - the implementation challenge of the WFD. European Commission, Luxembourg. 


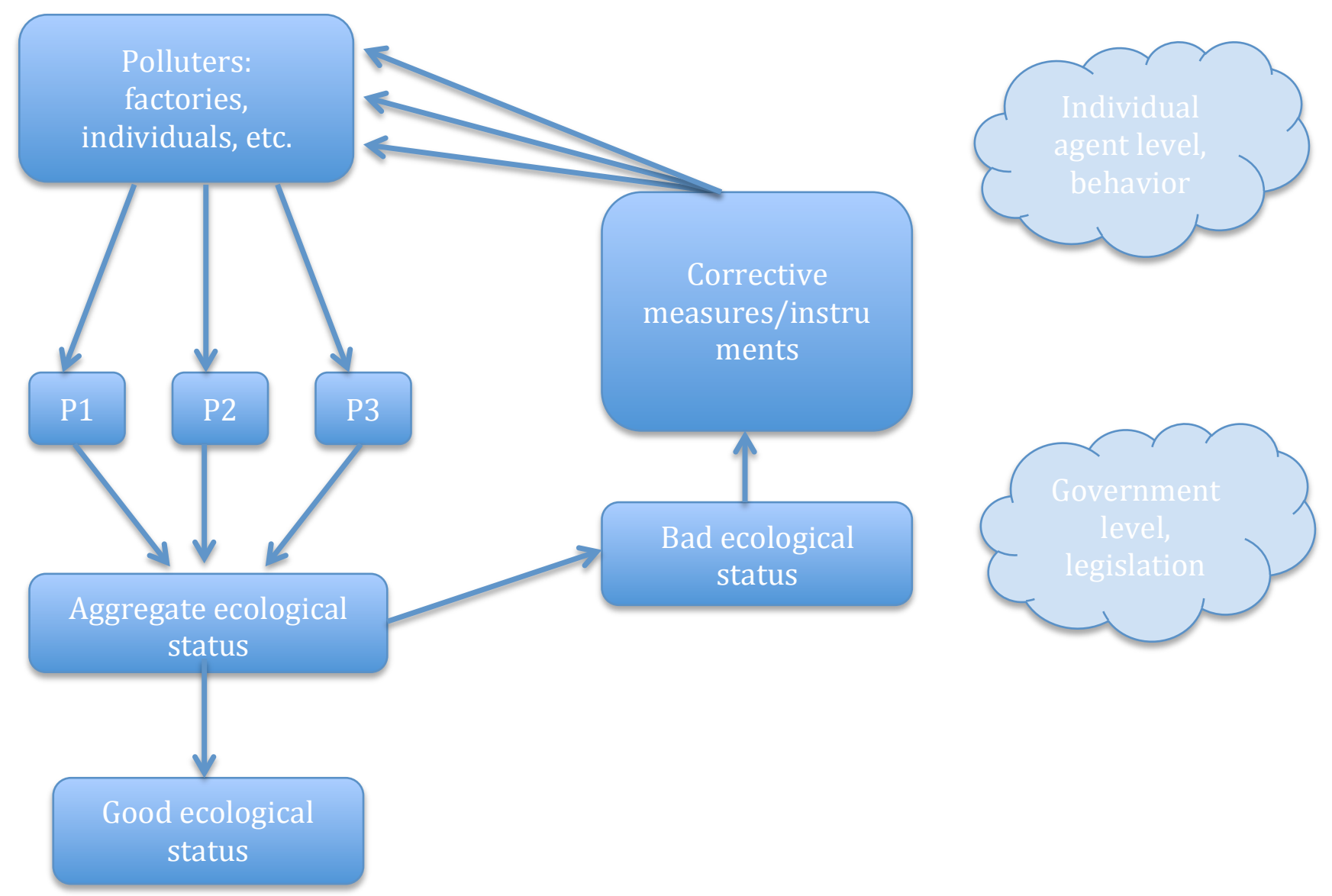

Figure 1 